\title{
A dimensão social e política da autonomia: ques- tões e percepções no ensino superior
}

\author{
Denise Aparecida Brito Barreto \\ Universidade Estadual do Sudoeste da Bahia \\ Albertina Lima Oliveira \\ Ana Maria Seixas \\ Universidade de Coimbra
}

\section{Resumo}

Este artigo está ancorado nos conceitos formulados e apresentados por Paulo Freire (1 996), autonomia como construção a partir de um espaço crítico e libertador, e José Contreras (2002), autonomia como um dos elementos da profissionalização, e objetiva refletir a forma como os docentes do ensino superior compreendem o significado de autonomia nos seus espaços e práticas profissionais. A pesquisa foi realizada em duas Universidades Públicas e duas Faculdades Particulares na cidade de Vitória da Conquista, no estado da Bahia, Brasil, com 25 professores que manifestaram a sua opinião sobre as temáticas em análise numa perspectiva comparativa, através de um questionário maioritariamente de respostas fechadas. Foi dada prioridade à pesquisa de abordagem quantitativa e descritiva e concluímos que, apesar do avanço no campo da autonomia, muito ainda se tem a fazer no domínio da reflexão e construção da autonomia docente, nos contextos analisados, e que há obstáculos importantes a serem superados.

Palavras-chave: Autonomia. Docência. Ensino Superior. Prática reflexiva.

\section{The social and political dimension of autonomy: questions and per- ceptions' in higher education}

\section{Abstract}

This article is anchored in the concepts formulated and presented by Paulo Freire (1996), autonomy as construction from a critical and liberating space, and José Contreras (2002), autonomy as one of the elements of professionalization, and aims to reflect how the higher education teachers understand the meaning of autonomy in their professional spaces and practices. The research was carried out at two public universities and two private colleges in Vitória da Conquista city, state of Bahia, Brazil, involving 25 professors who expressed their opinion about the themes under analysis in a comparative perspective through a questionnaire mostly composed of answers closed. 
A dimensão social e política da autonomia: questões e percepções no ensino superior

The priority was a research of quantitative and descriptive approach and we have concluded that, despite advances in the field of autonomy, much still has to be done in the domain of reflection and construction of professors' autonomy in the analyzed contexts, and there are important obstacles to be overcome.

Keywords: Autonomy. Teaching. Higher education. Reflexive Practice.

\section{La dimensión social y política de la autonomía: cuestiones y percep- ciones en la enseñanza superior}

\section{Resumen}

Este artículo está anclado en los conceptos formulados y presentados por Paulo Freire (1996), autonomía como construcción a partir de un espacio crítico y liberador, y José Contreras (2002), autonomía como uno de los elementos de la profesionalización, y objetiva reflejar la forma como los docentes de la enseñanza superior comprenden el significado de autonomía en sus espacios y prácticas profesionales. La investigación se realizó en dos universidades públicas y dos facultades privadas de la ciudad de Vitória da Conquista, en el estado de Bahía, Brasil, involucrando a 25 profesores que manifestaron su opinión sobre las temáticas en análisis desde una perspectiva 60 comparativa a través de un cuestionario mayoritariamente de respuestas cerradas. Se dio prioridad a la investigación de abordaje cuantitativo y descriptivo y concluimos que, a pesar del avance en el campo de la autonomía, todavía mucho aún se tiene que hacer en el ámbito de la reflexión y de la construcción de la autonomía docente, en los dos contextos analizados, y que hay obstáculos importantes a ser superados.

Palabras clave: Autonomía. Docencia. Enseñanza Superior. Práctica reflexiva.

\section{Introdução}

Neste artigo, assumiremos o conceito de autonomia fundamentalmente a partir da obra Pedagogia da Autonomia, de Paulo Freire (1996), e Autonomia de Professores (2002) de José Contreras. Utilizamos, como interlocução preferencial, as ideias de Paulo Freire que, na obra citada, apresenta um tratamento rigoroso na busca de uma resposta para a construção da autonomia dos sujeitos que serão pesquisados para a realização deste trabalho e José Contreras que, visando à compreensão da autonomia docente, em sua obra A autonomia de professores, sistematiza o profissional crítico-reflexivo 
com referências importantes entre a prática e a teoria, em sala de aula e meio social.

Conforme Freire (1996), no processo de autonomia é crucial o respeito à individualidade, por ser essa uma exigência ética convergente com a liberdade. A autonomia, na abordagem Freireana, deve ser uma construção, a partir do diálogo crítico e libertador em que a pessoa é encarada como sujeito e não como objeto, e uma conquista da própria liberdade. Neste sentido, a Educação deve proporcionar situações dialógicas propícias e apropriadas para que a autonomia aconteça. Autonomia é, portanto, uma disposição que é própria de duas esferas da vida humana: a ética e a política. Destarte, para Freire, a pedagogia da autonomia deve estar "[...] fundada na ética, no respeito à dignidade e à própria autonomia do educando" (FREIRE, 1996, p. 11 ). Na ética, não se tem um sujeito ético se ele não for autônomo, isto é, se ele não for capaz de, por si mesmo, deliberar a respeito das suas normas de ação e de pensamento, se não estiver liberto do medo de ser livre.

Contreras (2002) nos revela que o conceito de autonomia pode ser entendido como uma possibilidade de compreensão de um problema específico do ato de educar, sendo essa possibilidade essencial para a realização da prática educativa. Importante esclarecer que autonomia, nessa perspectiva, designa valor humano, condição para compreender as situações que podem emergir do espaço educativo e o que faz com que o docente desenvolva qualidades na sua prática educativa. $\bigcirc$ docente, entretanto, deve considerar a autonomia como possibilidade para compreender determinadas situações e, o seu perfil, caracterizado como perito, profissional reflexivo ou intelectual crítico será determinante para esse trabalho. Nessa ótica, podemos afirmar que a autonomia possibilita aos docentes, na sua prática educativa, promover a aprendizagem significativa e reflexiva capaz de transformar a realidade.

Paulo Freire (1996) e José Contreras (2002), através dos seus conceitos sobre Autonomia e as suas articulações no campo empírico, nos permitiram compreender que esse conceito se encontra no espaço onde o social e o político se articulam, em uma história atravessada por rupturas e descontinuidades, visto que, em cada tempo histórico, se adicionam relações de continuidade e de rupturas do passado, assim como surgem distintas probabilidades do futuro (KOSELLECK, 2006). Neste contexto, portanto, a análise das percepções dos professores pretende contribuir para a compreensão da dimensão social e 
política da autonomia e do processo de construção da autonomia docente em contexto de ensino superior.

Considerando necessária a discussão sobre autonomia e saberes teóricos e práticos considerados importantes pelos docentes, na sua profissão, tivemos como objetivo analisar, a partir dos questionários respondidos pelos docentes, o que é autonomia e como estão relacionados esses saberes profissionais, na sua prática. Paulo Freire e José Contreras foram escolhidos por terem elaborado amplas discussões acerca de autonomia e saberes docentes, e pela possibilidade de se complementarem. Pretendemos, deste modo, contribuir para uma compreensão sobre práticas pedagógicas e autonomia, a partir dos docentes que atuam em Universidades públicas e Faculdades particulares, e para que os resultados dessa pesquisa possam colaborar na melhoria do ensino-aprendizagem e relações interpessoais e ratificar a sua relevância para uma maior compreensão sobre o tema.

\section{A autonomia, a docência e a postura reflexiva}

62 individual. Conforme Contreras,

Na sua dimensão social, a autonomia é um processo coletivo, e não

A autonomia não pode ser analisada de uma perspectiva individualista ou psicologista, como se fosse uma capacidade que os indivíduos possuem. A autonomia, como os valores morais em geral, não é uma capacidade individual, não é um estado ou um atributo das pessoas, mas um exercício, uma qualidade de vida que vivem (CONTRERAS, 2002, p. 197).

Nesta mesma linha de pensamento Freire (1996) afirma que, na dimensão social, a autonomia docente não pode ser vista como capacidade privilegiada dos docentes e independente dos seus processos formativos. Ela se constitui nas situações de aprendizagem, em diversos contextos, o que implica o encontro entre os sujeitos, as estruturas particulares e as construídas na sociedade. Observamos que não basta vivenciar o contexto em que vivemos, é preciso também perceber o nosso estar inserido nesse contexto, ou seja, considerar as dimensões individual e social.

Na sua dimensão política, autonomia é o que define a democracia. Assim, a autonomia ganha sentido sócio-político-pedagógico quando significa 
libertação das opressões que restringem ou anulam a liberdade de um povo, ou quando em contexto de sala de aula se promove uma crescente liberdade, o que constitui a conquista da própria autonomia. Toda educação é política, por isso, "[...] as relações entre educação e política se dão na forma de autonomia relativa e dependência recíproca" (SAVIANI, 1983, p. 92-93). Ainda conforme Saviani (1983), a educação se subordina à política e esta exerce uma função educativa, uma vez que, em uma sociedade de classe, a prática política subordina a prática educativa, pois o primado da política reduz a margem de autonomia da educação. Na sua essência, a educação é política, pois ela não existe sem mudança. Consequentemente, todo ato educativo tem por fim transformar, conduzindo à emancipação do sujeito e à edificação de sociedades mais justas e igualitárias. Do mesmo modo, o ato educativo deve, sobretudo, investigar a amplitude e a abrangência das mudanças, ocorram quer nos níveis histórico, social ou individual.

Não existe neutralidade na educação. Essas práticas da autonomia exigem que o homem transponha condições de inércia e inconsciência para realizações mais conscientes. Dessa forma, a autonomia docente é indissociada dos direitos prescritos, contidos e assegurados nas políticas públicas do governo e àquele que interage com o mundo na busca de seus próprios direitos e os da sua comunidade. Uma dimensão do papel político do professor, como profissional político da educação, é sua capacidade de perceber que o que está posto, o que existe, pode ser diferente e essa orientação ao diferente, e a sua efetivação, o leva a um compromisso político e ético com os educandos e a sociedade, em geral. Para Freire (1996), a educação é um ato político por conter uma intencionalidade, nunca ser neutra e ser social.

Maciel (2001) nos assegura que os diferentes significados de autonomia, no decorrer da história humana, constituíram/vieram a ser concebidos também na acepção política ou como uma concepção de caráter político. Nessa linha de pensamento, o que esperamos dos docentes é que o seu envolvimento no processo educativo aponte a importância de suas ações, visando se esforçar e se responsabilizar em favorecer a ratificação ou construção de uma autonomia individual e coletiva, que promoverá, de acordo Castoriadis (1987), a construção de sujeitos, capazes de determinar a sua própria evolução histórica, pois, de acordo com esse autor, a liberdade de pensar e agir nos torna livres. 
Na perspectiva de Freire, entendemos política como a consciência que anuncia e denuncia as relações de poder que os sujeitos desempenham e aturam. Política pode ter, também, a conotação de discussões que assumem a forma de dialogicidade e que incorporam diferentes opiniões com relação às formas de poder que esses sujeitos desempenham e aturam, concomitantemente, ao compromisso orientado pela perspectiva ética que eles assumem com esses poderes.

$\bigcirc$ que podemos verificar, ainda de acordo com Contreras (2002), é que o alcance de tal autonomia dependerá do perfil do docente que se deseja assumir: se perito /o docente perito/tecnicista que apenas aplica técnicas já produzidas e que compreende os alunos no contexto em questão); o docente reflexivo (aquele que avança na reflexão da ação individual e coletiva em contextos ampliados; e o intelectual crítico lo docente que prossegue na busca do processo de transformação dos sujeitos e perpassa a relação sala de aula-escola-sociedade). Esses diferentes perfis se distinguem na observação dos seus princípios, meios e finalidades. A autonomia, assim depreendida, compreende visões diferentes de contexto, docente, discente, ensino e aprendizagem.

A título de exemplificação, refere Oliveira (2005 apud CANDY, 64 1991) que, para podermos considerar uma pessoa autônoma, devemos ter em consideração estes seis critérios: 1) formular propósitos e planos sendo pouco suscetível a pressões externas; 2) exercer liberdade de escolha, quer em pensamentos, quer em ações; 3) manifestar capacidade de reflexão, ponderando alternativas com base em crenças moralmente defensáveis e consistentes; 4) prosseguir com autodeterminação suficiente os seus planos de ação para os levar a bom termo, enfrentando os obstáculos e oposição que encontre; 51 manifestar um grande autodomínio emocional, em face de desafios, dificuldades e reveses; 6) ver a si própria como uma pessoa autônoma.

Deste modo, a alteração da situação do docente para a condição de profissional autônomo, advém da sua formação e ação reflexiva, da sua capacidade de inovação e de ética. A reflexão docente, portanto, apresenta-se como um grande divisor de águas entre os profissionais da educação. $\bigcirc$ docente que reflete sobre os seus atos oferece maior probabilidade de acertos nas suas decisões. Isso significa afirmar que apenas o domínio do conteúdo e de técnicas pedagógicas (instrumentalidade técnica) não é o bastante. Somente a partir da reflexão é que surgem as significações no sentido de ampliar a sua compreensão e atuação em relação a sua prática docente. 
Por outro lado, se o docente utiliza a prática reflexiva com a intenção tão somente do discurso da modernidade e da prática individual, de acordo com Pimenta (2005), essa ação responsabiliza o professor pelos problemas estruturais do ensino como, por exemplo, conduzi-lo a pensar que ele deve se incumbir na resolução dos problemas educativos.

Para especificar a diferença entre o docente que pratica a reflexão individual daquele cuja prática reflexiva alcança o social, econômico, político, enfim, o global, podemos afirmar que a reflexão é a ação utilizada enquanto prática que compreende o homem enquanto sujeito social, com desigualdades, limites e ultrapassa a simples relação professor/aluno que se encerra entre quatro paredes. Segundo Freire (1996, p. 96), "[...] o bom professor é o que consegue, enquanto fala, trazer o aluno até a intimidade do movimento do seu pensamento". Ele afirma que o diálogo é a melhor forma de interação e através dele o sentimento de respeito e autoridade se faz possível no ambiente escolar.

Contreras (2002) assegura que a autonomia, para existir, precisa de uma sociedade que se interesse em formar cidadãos críticos e emancipados. Nesse sentido, o processo ensino-aprendizagem necessita ser pautado em formas diferenciadas de consolidar as relações. E para que isso se concretize, o ambiente onde ocorrem essas ações precisa estar apoiado em bases democráticas com ideais de educação emancipatória bem alicerçados.

De acordo com Morin (1996), o sujeito é ator e autor de sua própria história e também de outras histórias sociais, pois ele se desenvolve em contextos que mantêm mútua dependência e, dessa forma, são múltiplas as influências das diversas situações das quais participa. Portanto, o conhecimento das relações que esse sujeito estabelece nos variados contextos é um aspecto, entre tantos outros, que promoverá a compreensão do seu potencial autônomo. A relação que ele imprime de dentro para fora, da forma como se organizará externamente, oferecer-the-á condições para que ele construa a sua autonomia.

A autonomia, portanto, é construída no encontro, onde se afirmam as finalidades profissionais. Nesse contexto, se estabelece o diálogo e o entendimento das perspectivas e expectativas sociais. A autonomia, quando compreendida como processo de reflexão sobre a própria construção docente, é eficaz. Se compreendida como um processo interior de compreensão e construção pessoal e profissional torna-se um processo dinâmico em um contexto 
de relações. A autonomia congrega, enfrenta e problematiza, nas relações docentes, convicções e inseguranças.

Nóvoa (1992, p. 10) afirma que "[...] ser professor obriga a opções constantes que cruzam a nossa maneira de ser com a nossa maneira de ensinar, e que desvendam na maneira de ensinar a nossa maneira de ser". Isso nos faz refletir a impossibilidade de separar o sujeito da sua ação, conforme defende também Contreras (2002). Freire (1996) compartilha desse posicionamento quando assegura que

A autonomia, enquanto amadurecimento do ser para si, é processo, é vir a ser. Não ocorre em data marcada. É neste sentido que uma pedagogia da autonomia tem de estar centrada em experiências estimuladoras da decisão e da responsabilidade, vale dizer, em experiências respeitosas da liberdade (FREIRE, 1996, p. 121).

Concordamos com Contreras (2002) quando afirma que, numa perspectiva autonômica, o docente encontra-se, permanentemente, em busca de aprendizagem e da reconstrução de seus saberes. A partir deste ponto, compreendemos que a problematização da função do professor é determinante 66 para perceber os processos de efetivação da autonomia no processo pedagógico. Assim, autonomia deverá ser ponderada como um processo que procura significar a prática pedagógica e contribuir como força auxiliar na transformação histórica da educação e da sociedade, ou seja, procuraremos descrever e explicar o significado de Autonomia em contexto de trabalho docente no ensino superior, auscultando os professores, através de questionário.

\section{Percurso metodológico da pesquisa: desvelando a produção dos dados}

Conforme propõe Ogliari (2007), pesquisar é analisar informações da realidade que se está estudando, por meio de um conjunto de ações e objetivos, é uma comunicação entre os dados coletados e analisados com uma teoria de base.

Assim, o percurso metodológico da pesquisa pretendeu, inicialmente, refletir sobre a dimensão política e social da autonomia docente, a qual nos conduziu à elaboração de um questionário como um instrumento de investigação capaz de captar, através das respostas dos docentes, a sua percepção 
sobre a forma como a autonomia está sendo praticada em duas Universidades Públicas e duas Faculdades particulares de Vitória da Conquista-Bahia.

Atribuímos prioridade à pesquisa de abordagem quantitativa e descritiva, por nos permitir comparar, de forma mais estruturada, as diferenças de opinião dos docentes entre duas Instituições Públicas e duas privadas. Gil (1999) afirma que a pesquisa descritiva tem como objetivo principal descrever, analisar ou estabelecer as relações entre fatos e fenômenos.

Esta pesquisa foi realizada em três etapas: revisão bibliográfica; na segunda etapa - questionário -, em formulário eletrônico, construído e disponibilizado em um endereço eletrônico criado através do suporte Google Forms². Foi solicitado pela pesquisadora principal às instituições o acesso aos e-mails dos docentes. Após a devolução dos formulários preenchidos, por e-mail, partimos para a terceira etapa, a análise quantitativa e descritiva dos itens/ questões integrantes do questionário.

\section{Instrumento}

Os nossos dados empíricos foram coletados através de aplicação de um questionário composto por dois grupos de questões fechadas à exceção de uma questão, aberta, pertencente ao segundo grupo. Conforme Gil ( 1999 , p. 1281, "[...] a técnica de investigação composta por um número mais ou menos elevado de questões apresentadas por escrito às pessoas, tendo por objetivo o conhecimento de opiniões, crenças, sentimentos, interesses, expectativas, situações vivenciadas etc".

$\bigcirc$ primeiro grupo procurou obter dados de caracterização sociodemográfica dos respondentes enquanto o segundo pretendeu identificar as percepções dos docentes sobre a autonomia em função da sua experiência docente e sua prática pedagógica. $\bigcirc$ Grupo 1 contempla os seguintes aspectos: caracterização docente e atividade docente (variáveis sexo, idade, formação acadêmica, tempo de docência, categoria profissional, regime de trabalho, cursos nos quais atua, natureza das aulas, participação além docência); e o Grupo 2 analisa a Formação docente e a Autonomia para ações docentes (definição da formação, decisões institucionais, metodologias de ensino, avaliação, planejamento, currículo, horários, etc.). A questão aberta interroga o ponto de vista e a importância da construção da autonomia docente, na contemporaneidade, no ensino superior. Assim, os questionários 
nos ofereceram condições para obtenção de informações sobre as duas instituições de ensino superior públicas e as duas privadas, possibilitando caracterizar e/ou diferenciar as ações dos docentes nesses dois espaços.

As questões fechadas do Grupo 2 são respondidas numa escala de Likert, de 1 a 5, que, segundo Spiegel (1975), é uma escala que requer dos sujeitos da pesquisa a indicação do seu grau de concordância ou discordância com as declarações relativas à atitude que está sendo medida. Em nossa pesquisa, utilizamos 5 - Concordo totalmente; 4 - Concordo parcialmente; 3 - Não concordo nem discordo; 2 - Discordo parcialmente; 1 - Discordo totalmente. Para a questão aberta, analisamos os elementos mais significativos sobre autonomia, contidos nas respostas dos docentes pesquisados. Utilizamos nomes próprios femininos e masculinos fictícios de origem portuguesa (Matilde, Carlota, Nuno Miguel e Ricardo Jorge), para representar os docentes que responderam aos questionários e, desta forma preservarmos a sua identidade.

\section{Contexto institucional da pesquisa e participantes}

contexto Institucional desta pesquisa foram duas Faculdades particu68 lares e duas Universidades públicas (uma Estadual e a outra Federal) na cidade de Vitória da Conquista-Bahia. A respeito da escolha das instituições, consideramos o fato de serem públicas e privadas, uma vez que esperamos que os níveis de percepção de autonomia sejam diferentes, e recolher dessa diferença elementos importantes para a reflexão sobre a autonomia nas Instituições de Ensino Superior. Assim, o critério principal observado para seleção dos docentes foi o de lecionarem, simultaneamente, em duas Instituições de Ensino Superior - uma privada e uma pública estadual ou federal. Esse critério foi pensado por entendermos que o docente que lecionou, nos dois setores de educação superior, vivenciou experiências divergentes, que marcaram a sua trajetória de vida e profissional, em várias situações.

A amostra desta pesquisa foi composta por vinte e cinco (25) docentes, professores de duas Universidades Públicas e duas Faculdades privadas, correspondendo a oitenta e seis por cento (86\%) de todos os docentes, o que é considerado uma taxa de resposta bastante significativa.

Inicialmente, as respostas apontadas pelos docentes foram alvo de uma análise descritiva geral e, posteriormente, procedemos a uma análise 
estatística inferencial, recorrendo a testes não paramétricos, para análise das diferenças entre as duas instituições públicas e as duas privadas.

\section{Caracterização sociodemográfica}

A partir dos dados dos sujeitos que fizeram parte dessa pesquisa, desenhamos alguns aspectos gerais e interessantes sobre a sua história acadêmica e profissional. Os docentes possuem formação acadêmica diferenciada (Administração, Ciências Contábeis, Direito, Enfermagem, Engenharia da Computação, Farmácia Bioquímica, Fisioterapia, Física, Letras, Odontologia, Pedagogia, História, Geografia) que os autorizam nas interpretações múltiplas, advindas dessas graduações, e, também, uma diversidade de significações com referência às questões sobre o regime de trabalho, formação continuada, mudanças, autoformação, metodologia, planejamento etc.

número de docentes do sexo masculino e feminino, das Instituições de Ensino Superior (IES), e que responderam ao questionário correspondeu, respectivamente a $52 \%$ e $48 \%$. Observamos que, nas IES pública e privada, há grande concentração de professores nos cursos de Administração, Ciências Contábeis, Engenharias, Fisioterapia e Direito. Por outro lado, somente nas IES públicas há referência dos cursos da área de Letras, Educação e História.

\section{Tabela 1}

\section{Distribuição dos professores pelos cursos lecionados (IES Pública e IES Privada)}

\begin{tabular}{lcc}
\multicolumn{1}{c}{ Cursos lecionados } & IES Pública (\%) & IES Privada (\%) \\
Administração & $4(16)$ & $2(8)$ \\
Administração, Comunicação Social & 0 & $1(4)$ \\
Administração, Engenharia(s), Farmácia/Administração, & 0 & $3(12)$ \\
Enfermagem, Fisioterapia/Administração, Engenharia & $1(4)$ & 0 \\
Comunicação Social/Cinema e Audiovisual & 1 & 0 \\
Biologia e Medicina & 0 & $1(4)$ \\
Enfermagem, Biomedicina & 0 & $1(4)$ \\
Enfermagem, Fisioterapia & 0 & $1(4)$ \\
Enfermagem, Farmácia, Fisioterapia, Estética e Cosmética & $1(4)$ & 0 \\
Engenharia(s), Física & & 0
\end{tabular}


A dimensão social e política da autonomia: questões e percepções no ensino superior

\begin{tabular}{lcc}
\multicolumn{1}{c}{ Cursos lecionados } & IES Pública (\%) & IES Privada (\%) \\
Educação, História & $1(4)$ & 0 \\
Fisioterapia & $6(24)$ & $3(12)$ \\
Odontologia & $1(4)$ & 0 \\
Direito, Engenharia(s), ciência da computação / Direito & $3(12)$ & $3(12)$ \\
Administração, Ciências Contábeis / Administração, & & \\
secretariado/Administração, Ciências Contábeis, & $1(4)$ & $4(16)$ \\
Fisioterapia & & $1(4)$ \\
Ciências Contábeis & $1(4)$ & $1(4)$ \\
Ciências Contábeis, Enfermagem, Farmácia & 0 & 0 \\
Educação, Letras & $1(4)$ & 0 \\
Ciências Contábeis, Direito & $1(4)$ & 0 \\
Educação & $1(4)$ & 0 \\
Letras & $1(4)$ & $3(12)$ \\
Arquitetura, Direito & 0 & $1(4)$ \\
Engenharia(s), Sistemas de Informação & $1(4)$ &
\end{tabular}

70 Com relação à idade dos docentes podemos, assim, distribuílos: $28 \%$ estão na faixa etária de 25 a 35 anos; $28 \%$ têm de 36 a 45 anos; e 44\% estão com idade entre 46 e 55 anos. Esses dados nos levam a concluir que a maioria dos professores que atua nesses espaços público e privado está em plena atividade, distante de se aposentar, pelas condições de permanência que o estatuto do magistério oferece.

$\bigcirc$ corpo docente de ambas as IES é muito bem qualificado. Isso decorre da exigência que, hoje, se impõe para a permanência e ascensão no quadro docente: $20 \%$ dos docentes têm especialização; 36\% têm mestrado; $36 \%$ têm doutorado, e 4\%, pós-doutorado. Esses valores traduzem o crescimento sem igual na qualificação docente nos últimos vinte anos.

Sobre o tempo de serviço (Tabela 2), convém destacar que encontramos, nas Instituições Públicas, docentes entre 21 e 25 anos de serviço (4\%), o que não ocorre nas Faculdades Privadas, onde o tempo maior corresponde a $0-5$ anos (36\%) ou 1 1-15 anos (36\%). Nas Universidades Públicas, a maior parte dos docentes tem 11 ou mais anos de serviço (56\%). Esse dado ratifica a mudança de regime de trabalho do docente para Dedicação Exclusiva, traduzindo a tendência de o docente procurar por estabilidade na Universidade 
Pública, no avançar da idade, e diminuir ou mesmo dispensar o trabalho nas Instituições de Ensino Superior Privadas.

Observamos que todos os professores apresentam vivências e familiaridade com o ensino superior, especificamente com a docência. Constatamos, também, que, pelo tempo de serviço, todos têm grande experiência. De fato, ser professor é um processo complexo que necessita de tempo para que esse papel venha a ser refletido e elaborado. "Um tempo para refazer identidades, para acomodar inovações, para assimilar mudanças" (NÓvOA, 1995, p. 16). Compete-nos analisar a referida situação, pois, se de um lado a experiência pode ajudar no desenvolvimento do processo reflexivo e emancipatório, por outro poderá resultar em práticas automáticas e de maior pendor tecnicista.

$\bigcirc$ regime de trabalho docente este dependerá de determinadas condições, entre elas o tempo que o docente disponibiliza para assumir disciplinas lquem se encontra em regime de Dedicação Exclusiva (DE) está impossibilitado de atuar em outros espaços, para além da Universidade Pública), possuir outra fonte de trabalho, ou mesmo o seu interesse por determinada carga horária. Essas recomendações valem para as IES privadas que se encontram numa condição subalterna às Instituições Públicas (os docentes das Instituições Públicas disponibilizam a sua agenda, primeiramente, a estas Instituições). Percebemos, na Tabela 2, como estão distribuídas as cargas horárias nas duas Instituições públicas e das duas Privadas.

\section{Tabela 2}

\section{Distribuição dos docentes por regime de trabalho e setor de ensino}

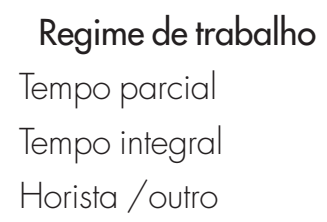

Total
IES Públicas

$4(16 \%)$

$21(84 \%)$

$010 \%$

$25(100 \%)$
IES Privadas

$10(40 \%)$

$4(16 \%)$

$11(44 \%)$

$25(100 \%)$

Observamos que os docentes que atuam nas Instituições públicas o fazem, na sua maioria, em tempo integral (40h), carga horária que possibilita atuação do docente, também, nos dois espaços, porém, disponibilizando para as Faculdades privadas apenas 20 horas semanais. Aqueles docentes que estão inseridos no tempo parcial (2Oh) disponibilizam quarenta horas 
A dimensão social e política da autonomia: questões e percepções no ensino superior

(40h) semanais para as Faculdades privadas, cumprindo uma carga horária de sessenta horas semanais.

Na Tabela 2, acima, o resultado nos mostra o grande interesse das Faculdades particulares em manter os seus professores em Tempo Integral Inenhum professor que fez parte desta pesquisa pode assumir Dedicação Exclusiva nas particulares, haja vista a soma de carga horária exceder o permitido), justamente por essa carga horária tornar-se mais adequada para a organização do processo pedagógico, reconhecendo-se que essa disponibilidade será de grande significância para maiores e melhores produções na formação dos discentes.

\section{Resultados estatísticos descritivos e inferenciais relativos à percepção dos professores}

\section{Tabela 3}

Percentagem de resposta aos itens em função de setor público e privado e teste das diferenças de percepção dos professores

\begin{tabular}{|c|c|c|c|c|c|c|c|c|c|c|c|}
\hline \multirow[b]{2}{*}{ Itens } & \multicolumn{5}{|c|}{ IES Públicas } & \multicolumn{5}{|c|}{ IES Privadas } & \multirow[b]{2}{*}{$P$} \\
\hline & 1 & 2 & 3 & 4 & 5 & 1 & 2 & 3 & 4 & 5 & \\
\hline $\begin{array}{l}\text { 1. A possibilidade de participar das } \\
\text { definições/decisões políticas da IES } \\
\text { estimularia a minha prática docente. }\end{array}$ & 4 & 0 & 8 & 60 & 28 & 0 & 4 & 16 & 32 & 48 & .449 \\
\hline $\begin{array}{l}\text { 2. Há autonomia de decisão sobre } \\
\text { a própria formação continuada }\end{array}$ & 4 & 32 & 16 & 24 & 24 & 28 & 20 & 16 & 32 & 4 & .086 \\
\hline $\begin{array}{l}\text { 3. A gestão do currículo é irrelevante } \\
\text { para a autonomia pedagógica. }\end{array}$ & 80 & 8 & 8 & 4 & 0 & 56 & 12 & 20 & 4 & 8 & $.036 *$ \\
\hline $\begin{array}{l}\text { 4. Na IES é respeitada a autonomia } \\
\text { individual. }\end{array}$ & 8 & 24 & 16 & 40 & 12 & 36 & 36 & 4 & 24 & 0 & .001 * \\
\hline $\begin{array}{l}\text { 5. Os professores são resistentes à } \\
\text { mudança. }\end{array}$ & 4 & 12 & 12 & 48 & 24 & 4 & 12 & 4 & 60 & 20 & .754 \\
\hline $\begin{array}{l}\text { 6. A possibilidade de participar na } \\
\text { tomada de decisão em órgãos de } \\
\text { gestão pode melhorar minha prática } \\
\text { docente. }\end{array}$ & 4 & 4 & 8 & 32 & 52 & 4 & 4 & 20 & 20 & 52 & .537 \\
\hline $\begin{array}{l}\text { 7. O meu envolvimento na definição } \\
\text { das ações de planejamento tem sido } \\
\text { relevante. }\end{array}$ & 8 & 4 & 24 & 28 & 36 & 8 & 8 & 20 & 32 & 32 & .750 \\
\hline
\end{tabular}


Denise Aparecida Brito Barreto | Albertina Lima Oliveira | Ana Maria Seixas

\begin{tabular}{|l|c|c|c|c|c|c|c|c|c|c|c|}
\hline \multirow{2}{*}{ Itens } & \multicolumn{5}{|c|}{ IES Públicas } & \multicolumn{5}{|c|}{ IES Privadas } & \\
\cline { 2 - 12 } & 1 & 2 & 3 & 4 & 5 & 1 & 2 & 3 & 4 & 5 & P \\
\hline $\begin{array}{l}\text { 8. A formação contínua só faz } \\
\text { sentido se enraizada nas situações } \\
\text { concretas de trabalho. }\end{array}$ & 0 & 28 & 12 & 32 & 28 & 12 & 12 & 20 & 40 & 16 & .326 \\
\hline $\begin{array}{l}\text { 9. Participação na organização } \\
\text { e escolha de ações de formação } \\
\text { contínua }\end{array}$ & 4 & 0 & 16 & 32 & 48 & 4 & 0 & 16 & 40 & 40 & .565 \\
\hline $\begin{array}{l}\text { 10. A livre escolha da metodologia } \\
\text { de ensino possibilita a adaptação } \\
\text { da abordagem dos conteúdos ao } \\
\text { público-alvo. }\end{array}$ & 0 & 12 & 4 & 24 & 60 & 0 & 28 & 4 & 32 & 36 & $.002^{*}$ \\
\hline
\end{tabular}

Legenda | IES: Instituições de Ensino Superior; 1: Discordo Totalmente; 2: Discordo; 3: Nem Concordo Nem Discordo; 4: Concordo; 5: Concordo Totalmente; p: probabilidade teste Wilcoxon Signed Rank ( $\left.{ }^{*} \mathrm{p}<.05\right)$.

\section{Discussão dos resultados}

Na Tabela 3, apresentam-se as estatísticas descritivas dos 10 itens do questionário e as estatísticas inferenciais de teste das diferenças entre Instituição Pública e Privada, em função de cada item. Como vemos na tabela, só há diferenças significativas nos itens 3,4 e 10. Todas as restantes respostas, embora em termos absolutos difiram, não se pode considerar estatisticamente diferentes.

Os itens 1 e 7 vão, no mesmo sentido, reconhecendo que a participação dos professores de ambas as instituições (públicas e privadas) nas definições/decisões políticas estimularia a sua prática docente litem 1, 88\%; $80 \%$, respectivamente públicas e privadas; $p=.449$ ) e que o seu envolvimento na definição das ações de planejamento tem sido relevante (item 7, 80\%; $80 \%$, respectivamente públicas e privadas; $p=751$.

De tal maneira, apresenta-se a autonomia de decisão sobre a própria formação continuada (ltem 2, p=.086), como espaço e tempo de reflexão e de produção pedagógica, contribuindo e estimulando os professores a assumir a responsabilidade de seu próprio desenvolvimento profissional e pessoal. A maioria das respostas encontram-se em Concordo e Concordo totalmente 148\%; 36\%, respectivamente públicas e privadas). Baseada na produção dialética do conhecimento, a formação continuada como processo de construção e reconstrução de saberes docentes, desafia para produzir conhecimentos e 
A dimensão social e política da autonomia: questões e percepções no ensino superior

criar estratégias práticas de ações, pois o educador terá que construir novos saberes docentes direcionados para o ensino-aprendiz agem, (re)significando sua práxis pedagógica.

Devido à gestão do currículo ser irrelevante para a autonomia pedagógica, obtivemos como resultado a discordância total, 80\% lou 88 \% se incluirmos também os que discordam) dos docentes da IES pública e 56\% (ou $68 \%$, incluindo os que discordam) dos docentes da IES privada. Desta forma, percebemos que as respostas dos docentes são muito mais discordantes nas IES Públicas do que nas IES Privadas, sendo a diferença significativa (item 3, $\mathrm{p}=.036)$.

currículo deve ser construído visualizando as necessidades locais, e, de acordo com Nilda Alves (2002), o currículo é um saber que se constrói diariamente e a partir de dentro da escola. Essa referência aponta os problemas que atingem os discentes e a sociedade. Deparamo-nos, muitas vezes, com currículos que não atendem às necessidades da nossa comunidade acadêmica, cuja rigidez curricular trava possibilidades. Ainda de acordo com Nilda Alves (2002), devemos pensar que o currículo não deveria se resumir a determinações oficiais mas ser construído no espaço-tempo da escola, através

74 de acordos e mudanças a serem revistos e refletidos quase quotidianamente, e não através de determinações legais.

No que concerne ao respeito pela autonomia docente, as opiniões divergem drasticamente em ambas as instituições (duas públicas e duas privadas). Enquanto 40\% dos docentes das IES públicas concordam parcialmente com essa questão, os outros $24 \%$ das privadas afirmam que não há respeito pela autonomia docente. Por outro lado, 32\% das IES Públicas discordam contra $72 \%$ nas IES Privadas (item 4, $p=.001$ ). Sobre essa questão, Freire (1996, p. 92) assegura que, para haver autonomia docente é preciso que haja competência profissional do educador, o que não significa o autoritarismo, mas sim uma qualificação a essa figura que é de extrema importância, porém, não suficiente. "[...] Não há nada que mais inferiorize a tarefa formadora da autoridade com que a mesquinhez com que se comporte". Nesse item, a autonomia emerge como fator de desenvolvimento do trabalho docente e da instituição educativa. 
No contexto da prática educativa, a autonomia deve ser entendida como um processo de construção permanente, no qual devem ser conjugados, equilibrados e fazer sentido muitos elementos.

Os docentes, quando questionados sobre resistência a mudanças, foram enfáticos em afirmar que concordam parcialmente com essa assertiva (48\% IES pública; 60\% IES privada). Vimos uma maior expressividade dessa afirmativa nas IES privadas (embora não seja a diferença significativa (item 5, $\mathrm{p}=.754)$.

Esse posicionamento dos docentes nos remete a Tardif (2002) quando esse autor apresenta a importância das rotinas para a manutenção da cultura viva. Ele afirma que as ações que fazem parte do cotidiano escolar devem permanecer. Porém, essas ações devem ter um tratamento diferenciado, devem estar revestidas do senso de crítica e do processo de reflexão permanente, gerando possibilidades de novas produções. Na atualidade, percebemos que os docentes adquiriram mais autonomia para reinventar a sua prática, criando e inovando suas atividades educativas, haja vista estarem constantemente em evolução, e o saber da experiência poder the conferir maior autonomia profissional.

Dessa forma, para contribuir com esse argumento, Tardif (2002, p. 39) postula que "[...] os saberes são elementos constitutivos da prática docente". Nessa seara, o desenvolvimento da prática pedagógica permite ao professor uma relação de autonomia, criando propostas de intervenção pedagógica, lançando mão de procedimentos, recursos e conhecimentos pessoais disponíveis no contexto, integrando saberes, sensibilidade e intencionalidade para responder a situações complexas e diferenciadas nas práticas pedagógicas.

Considerando a formação continuada, os docentes das IES públicas e privadas defendem que ela deve estar enraizada nas situações concretas de trabalho (ltem $8, p=.326$ ) e atribuíram-lhe grande importância, embora mais os professores em IES públicas (28\% públicas; $16 \%$ privadas).

Desta forma, o processo de formação no ensino superior implica a imersão de uma reelaboração de práticas, no sentido de perceber mediante ações reflexivas a produção dos saberes mobilizados no processo de formação inicial do professor. Quando o professor se emancipa, através de práticas reflexivas, ele passa a ter mais autonomia e a refletir na ou sobre a ação (ZEICHNER, 1993). 
Conforme Contreras (2002), a autonomia no contexto da prática educativa deve ser entendida como um processo de construção permanente, no qual devem ser conjugados, equilibrados e fazer sentido muitos elementos.

Com referência à participação na organização de ações de formação continuada e escolha da formação que mais thes interessa, os docentes responderam positivamente (ltem $9, p=.565$ ), sendo essas opiniões partilhadas por ambos os grupos, público (48\%) e privado (40\%).

Além dessas respostas, necessitamos do desenvolvimento de uma cultura de colaboração que valorize, significativamente, os espaços organizacionais, profissionais, curriculares e de ensino. Para Freire (1996), é, na formação permanente dos professores, que se encontra o momento fundamental da reflexão crítica sobre a prática.

Com relação à participação nas decisões institucionais e tomada de decisões, os docentes de ambas IES, públicas e privada, afirmaram que essa participação melhora e estimula a sua prática, uma vez que as respostas não se distinguem significativamente (item $6, p=.537$ ) e estão concentradas em Concordo e Concordo Totalmente 184\%; 72\%, respectivamente públicas e privadas).

Refletindo sobre a liberdade de escolha da metodologia e conteúdos, observamos que houve uma diferença altamente significativa nas respostas dos docentes das IES públicas e privadas referindo os primeiros muito mais liberdade que os segundos (Item 10, p=.002). Esse resultado parece-nos ter a ver com a condição de um planejamento formatado, inclusive com indicação metodológica, para os docentes das IES privadas, enquanto os docentes das IES públicas consideram mais pertinente a liberdade na escolha da metodologia. Por terem diversas atribuições falta-thes tempo para planejar e, sendo assim, a possibilidade de ter um planejamento pronto é-lhes conveniente.

\section{Resultados qualitativos}

Partimos para analisar a única questão subjetiva que nos possibilitou "ouvir" os docentes sobre aspectos que eles puderam mencionar como importantes para a construção da autonomia docente, na contemporaneidade. Após analisarmos as respostas apresentadas pelos vinte e cinco professores, para a única questão subjetiva, entendemos que as respostas oferecidas por 
quatro docentes (Nuno Miguel, Ricardo Jorge, Matilde Luís e Carlota Manuel) contemplavam e sintetizavam as respostas oferecidas por todos os docentes que participaram desta pesquisa. Destarte, assim procedemos para a escolha dos quatro docentes para a análise da questão subjetiva. Escrevemos algumas respostas para entendermos as significações construídas por esses docentes a respeito da construção da autonomia. $\bigcirc$ professor Nuno Miguel nos afirma que

Com relações de trabalho precarizados e com a mercantilizacão do ensino superior não há possibilidade de se discutir autonomia docente nas IES privadas. A discussão não é colocada porque há outros e piores problemas a se resolver, como a 'industrialização', 'taylorização' do ensino que dissolve a relação de ensino aprendizagem e as resume em dar aulas e receber a parca remuneração. A qualificação docente cai a olhos vistos e o ensino superior torna-se, cada vez mais, uma extensão do colégio de segundo grau (NUNO MIGUEL, 2016).

ensino brasileiro, nestas últimas décadas, tem passado por bastantes transformações. Criou-se um modelo de crescimento do ensino pago, com financiamento público e privado que facilitou a inserção de pessoas que, talvez, nunca tivessem oportunidade de frequentar uma Universidade Pública e Privada. A educação, de alguma forma, tornou-se um negócio rentável, mas que também oferece mão de obra qualificada para o mercado e, em pouquíssimos centros de excelência, a pesquisa garante a inovação para as grandes empresas. As IES acolhem cada vez mais um público sedento de curso superior/diploma, que, por estarem afastados da escola por muitos anos, necessitam de uma nova forma de se fazer educação. Nuno Miguel, na sua resposta, aponta para uma realidade que ele vivencia e que sabemos ser reflexo de muitas outras realidades.

Desta forma, para a educação assumir um papel social significativo, são necessárias responsabilidade e autonomia por parte daqueles que mediatizam os saberes, saberes esses que buscam superar as interfaces do processo educacional, que não são poucos, mas precisam ser analisados e postos, talvez como referências para a produção de atitudes criadoras. Valemo-nos de Paulo Freire (1996, p. 58) quando diz que é na inconclusão do ser, que se sabe como tal, que se funda a educação como processo permanente. 
A dimensão social e política da autonomia: questões e percepções no ensino superior

Ricardo Jorge ratifica e complementa Nuno Miguel, quando declara que

No contexto das IES Públicas acredito ser importante que houvesse uma compatibilidade verdadeira entre a carga horária e o plano de trabalho. Trabalhamos muito mais do que as 40 horas que podemos oficializar, o que compromete sobremaneira nossa qualidade de vida (tanto docente quanto pessoal) e nos impede de avançar em determinados percursos de formação e de docência. No contexto das IES privadas, levando em conta a minha experiência, a autonomia docente fica comprometida, em grande medida pela falta de visão/qualificação daqueles que estão responsáveis pela gestão da instituição (RICARDO JORGE, 2016).

Observamos que a intensificação da carga de trabalho não afeta apenas a qualidade de vida, conforme afirma Ricardo Jorge. Essa carga horária excessiva também pode ser um obstáculo para os professores que precisam de qualificação, de formação contínua, para inclusive continuarem a exercer a profissão de professor (respondendo adequadamente às novas exigências). Segundo ele, a carga excessiva de trabalho impede a formação contínua e, 78 consequentemente, nós acrescentamos, pode se tornar um obstáculo à progressão na carreira acadêmica e à qualidade global do processo de ensino e aprendizagem.

No âmbito público, na prática, muitas decisões são refletidas e tomadas de forma colegiada, porém, não são implementadas porque o poder governamental não disponibiliza recursos. Então, participamos, decidimos, mas não há efetivação da autonomia, o que acaba minando a vontade em participar coletivamente da construção e da busca pela qualidade e autonomia docente. Nos aspectos pedagógicos e metodológicos há sim AINDA uma relativa autonomia, o que faz com que o trabalho docente seja recompensante e de qualidade. No âmbito das críticas ao privado. É uma lógica de patrão-empregado e cliente-fornecedor [...] uma mercantilização! A IES não se interessa nem um pouco pela autonomia docente Só o lucro e a diminuição de custos é o que interessa (RICARDO JORGE, 2016, grifo do autor).

Matilde Luís resgata o que já foi registrado sobre uma "falsa" autonomia ao afirmar que as decisões são tomadas em consenso, porém, não são acatadas. Mas afirma que no pedagógico ainda se vislumbra a autonomia, 
que promove um bom ensino. A docente acentua a disparidade entre as duas Instituições de Ensino Pública e as duas de Ensino Privado, quando denuncia o trabalho realizado na Instituição privada e a aspiração do aluno que frequenta aquele espaço.

Acredito que a autonomia docente seja determinante na condução de processos de ensino-aprendizagem em qualquer nível, visto que em qualquer sala de aula, há uma heterogeneidade que influencia na forma como as práticas pedagógicas se desenvolvem. Nesse sentido, a metodologia, os conteúdos, as formas de avaliação devem ser vinculadas a cada realidade. Isso não quer dizer, no entanto que o docente deva desenvolver um trabalho totalmente individualizado e solitário. As reuniões institucionais, os encontros pedagógicos podem, com a participação dos docentes, oferecer possibilidades diferenciadas de práticas pedagógicas. Nos tempos atuais, é a ação reflexiva que auxiliará a prática inovadora e autonomia docente (MATILDE LUÍS, 2016).

Aspectos que foram discutidos em todo o texto como, por exemplo, a importância do contexto local para a gestão curricular, o valor das formações continuadas para o trabalho docente, a reflexão para construção da autonomia e de uma prática pedagógica que atenda à heterogeneidade, são retomados por Carlota Manuel (2016) que ratifica cada aspecto citado acima como de extrema necessidade para o fazer/ser docente.

Em suas narrações sobre "Aspectos importantes para a construção da autonomia docente", a pergunta subjetiva que consta do questionário desta pesquisa, os docentes, em grande maioria, abordaram que um grande desafio na contemporaneidade se localiza na complexidade da práxis docente. Eles afirmam que a necessidade de reflexões é mais urgente do que a própria formação continuada, pois não adianta a formação continuada se o docente não reflete as suas práticas. E advertem que os docentes devem analisar com cuidado o momento que vivemos, de informações e relações imediatas. E esse processo é um sinal para a necessidade do repensar a educação. Conforme Freire (1996), o mundo não é. $\bigcirc$ mundo está sendo. Como subjetividade curiosa, inteligente, interferidora na objetividade com que dialeticamente me relaciono, meu papel no mundo não é só de quem constata o que ocorre mas também o de quem intervém como sujeito de ocorrências. 
Partindo do pensamento desses docentes, acreditamos que, para as práticas pedagógicas serem modificadas, são necessários tempo e cautela. Isto porque elas estão enraizadas historicamente e necessário se faz organizar novos pressupostos para dar contornos à emergência de uma nova práxis pedagógica. Contudo, com o advento de novas pesquisas e dos seus resultados, na área, concordamos com André (1997, p. 123) quando nos assegura que "A pesquisa pode tornar um sujeito professor capaz de refletir sobre sua prática profissional e de buscar formas [...] que o ajudem a aperfeiçoar cada vez mais seu trabalho docente".

Interessados em querer compreender o que imprime sentido a sua ação, apreendendo a sua intimidade pedagógica como um caminho de possibilidades para estabelecer um confronto com a história da autonomia docente, o educador, mais uma vez, é o sujeito que dará respostas às inquietações dos problemas geridos no espaço educacional e, em especial, no Ensino Superior.

\section{Considerações finais}

As reflexões empreendidas neste estudo possibilitaram descortinar aspectos significativos sobre autonomia docente no ensino superior, como também os encantos e desencantos, limitações e perspectivas neste campo de ação e produção do saber. Foi possível compreender que os docentes têm consciência da importância da reelaboração dos saberes que estão em permanente construção, a qual provém, na sua grande maioria, da ascendência gerada pela sua formação acadêmica, sua história pessoal, pelas experiências profissionais construídas no ambiente educacional e pela relação com seus pares no exercício das práticas docentes. Esses docentes também destacaram a necessidade de uma reestruturação nas políiticas de educação, onde se evidenciem melhores condições de trabalho, de pesquisa e de formação continuada. Perante as denúncias dos professores, estamos convictos de seu nível de consciência em relação a sua formação, mas deduzimos, também que, diante do contexto que se apresenta não se pode ficar a esperar que as reformulações aconteçam sem que haja uma política no sentido de solicitar encaminhamentos. Os docentes compreendem que a docência é o caminho que possibilita o processo de formação. Para tanto, exige do educador um investimento pessoal e institucional em sua formação permanente, pois, sendo 
a prática pedagógica fundamentada numa perspectiva reflexiva é necessário validar o exercício da docência. As respostas dos docentes revelam o seu grau de comprometimento com a produção do saber no ensino superior. Eles afirmam que devemos priorizar aprendizagens significativas, alicerçadas em práticas emancipadas e éticas. Para tanto, cada professor, diante de suas subjetividades, buscará o caminho para ações criadoras no processo de formação profissional. Os resultados dos dados da pesquisa nos revelaram que, para que haja uma reflexão e construção de autonomia docente, muito se tem a fazer. Eles apontam, também, a necessidade de políticas públicas que, através de ações significativas, cooperem com a sociedade. Em todo esse trajeto, a autonomia docente deve estar sendo atentamente observada e só terá sentido se atrelada à questão da autonomia das Faculdades privadas e Universidades públicas que devem ter clareza de seu papel social e político. Esperamos, diante do que foi posto, que este artigo sirva de referências para o incentivo às novas pesquisas e que promova reflexões para aqueles que tenham interesse em discutir e estudar sobre autonomia docente, reconhecendo a complexidade deste tema que abriga diferentes interpretações e que sinaliza para a continuação do debate.

\section{Notas}

1 Este artigo é produto do Pós-doutoramento realizado na Faculdade de Psicologia e Ciências da Educação - FPCE/Universidade de Coimbra/UC, em 2016, financiado pelo Conselho Nacional de Desenvolvimento Científico e Tecnológico (CNPq).

2 Google Forms: https://docs.google.com/forms/d/1SnHzKqDWSLgW6MKL3bLrKHAHPGJkfR C3fVT3gor84_Y/viewform?edit_requested=true

\section{Referências}

ALVES, Nilda (Org.). Criar currículo no cotidiano. 3. ed. São Paulo: Cortez, 2011.

ANDRÉ, Marli Eliza Dalmazo de Afonso. O papel mediador da pesquisa no ensino de didática. In: ANDRÉ, Marli Eliza Dalmazo de Afonso; OLIVEIRA, Maria Rita Neto Sales Oliveira (Org.). Alternativas no ensino da didática. 8. ed. Campinas: Papirus, 1997.

CANDY, Philip. Self-direction for lifelong learning. San Francisco, CA: Jossey-Bass, 1991. 
A dimensão social e política da autonomia: questões e percepções no ensino superior

CASTORIADIS, Cornelius. Encruzilhadas do labirinto. Rio de Janeiro: Paz \& Terra, 1987.

CONTRERAS, José. A autonomia de professores. São Paulo: Cortez, 2002.

FREIRE, Paulo. Pedagogia da autonomia. 9. ed. Rio de Janeiro: Paz \& Terra, 1996.

FREITAS, Helena Costa Lopes de. Formação de professores no Brasil: 10 anos de embate entre projetos de formação. Educação \& Sociedade, Campinas, v. 23, n. 80, ago. 2002, 1-32.

GIL, Antônio Carlos. Métodos e técnicas de pesquisa social. São Paulo, Atlas, 1999.

JORGE, Ricardo. Entrevista. Vitória da Conquista (Bahia), 16 mar. 2016.

KOSELLECK, Reinhart. Futuro passado: contribuição à semântica dos tempos históricos. Rio de Janeiro: Contraponto: Editora PUC-Rio, 2006.

LUIS, Matilde. Entrevista. Vitória da Conquista (Bahia), 16 mar. 2016.

MACIEL, Iria Maria. A questão da formação: tecendo caminhos para a construção da autonomia. In: MACIEL, Iria Maria (Org.). Psicologia e Educação: novos caminhos para a formação. Rio de Janeiro: Ciência Moderna, 2001.

MANUEL, Carlota. Entrevista. Vitória da Conquista (Bahia), 16 mar. 2016.

MIGUEL, Nuno. Entrevista. Vitória da Conquista (Bahia), 16 mar. 2016.

MORIN, Edgar. A noção de sujeito. In: SCHNITMAN, Dora Fried (Org.). Novos paradigmas, cultura e subjetividade. Porto Alegre: Artes Médicas, 1996.

NÓvOA, Antônio (Org.). Os professores e a sua formação. Portugal: Dom Quixote, 1992.

NÓVOA, Antônio (Org.). Vidas de professores. 2. ed. Porto: Editora Porto, 1995.

OGLIARI, Lucas Nunes. Pesquisar é analisar dados: uma constante (re) construção da realidade. In: GALIAZZI, Maria do Carmo; AUTH, Milton; MANCUSO, Ronaldo (Org.): Construção curricular em rede na educação em ciências: uma proposta de pesquisa na sala de aula. ljuí: Editora Unijuí, 2007.

OLIVEIRA, Albertina Lima. Aprendizagem autodirigida: um contributo para a qualidade do ensino superior. 2005. 492f. Tese (Doutorado em Educação Permanente e Formação de Adultos). Universidade de Coimbra, Faculdade de Psicologia e de Ciências da Educação, 2005.

PIMENTA, Selma Garrido, GHEDIN, Evandro (Org.). Professor reflexivo no Brasil: gênese e crítica de um conceito. 3. ed. São Paulo: Cortez, 2005. 
SAVIANI, Demerval. Escola e democracia. São Paulo: Cortez/Autores Associados, 1983.

SIEGEL, Sidnei. Estatística não-paramêtrica. São Paulo, Mcgraw-Hill, 1975.

SPIEGEL, Murray Ralph. Estatística. Rio de Janeiro. McGraw-Hill, 1975.

TARDIF, Maurice. Saberes docentes e formação profissional. 2. ed. Petrópolis: Vozes, 2002.

ZEICHNER, Kenneth. A formação reflexiva de professores: idéias e práticas. Lisboa: Educa, 1993.

Profa. Dra. Denise Aparecida Brito Barreto

Universidade Estadual do Sudoeste da Bahia

Departamento de Estudos Linguísticos e Literários Vice-coordenadora do Programa de Pós-Graduação em Educação

Grupo de Pesquisa Linguagem e Educação | GPLEd Grupo de Pesquisa Linguagem e Tecnologia | GPLIT

E-mail | deniseabrito@gmail.com

Profa. Dra. Albertina Lima de Oliveira Universidade de Coimbra

Faculdade de Psicologia e Ciências da Educação Pesquisadora do Centro de Estudos Interdisciplinares do séc. XX | CEIS20 E-mail | aolima@fpce.uc.pt

Profa. Dra. Ana Maria Seixas

Universidade de Coimbra

Faculdade de Psicologia e Ciências da Educação Grupo de Pesquisa do Centro de Estudos Sociais | CES E-mail | anaseixas@fpce.uc.pt

Recebido 26 ago. 2017 Aceito 25 set. 2017 